\title{
Imbalances Caused by SARS-CoV-2 during Pregnancy: Consider- ations for Long-Term Obstetric and Gynecological Care
}

\author{
João Victor Farias da Silva, MSc ${ }^{1}$ and Valdeci Elias dos Santos Jr, PhD ${ }^{2^{*}}$ \\ ${ }^{1}$ Medicine Department, Federal University of Sergipe, Maceió City, State of Alagoas, Brazil \\ ${ }^{2}$ Department of Dentistry, Head of Research and Post-Graduate Studies, Federal University of Alagoas, \\ Maceió City, State of Alagoas, Brazil
}

*Corresponding author: Valdeci Elias dos Santos Jr, PhD, Department of Dentistry, Maceió City, Federal University of Alagoas, State of Alagoas, Avenue Lourival de Melo Mota, S/N, Tabuleiro dos Martins, Brazil, Tel: +55-82-3214-1162

\begin{abstract}
SARS-CoV-2, responsible for the outbreak of severe acute respiratory syndrome corona virus 2 and the current pandemic, is one of seven species of coronavirus that infect humans and is among the three that are potentially fatal. Its pathophysiology, although not fully understood, has been characterized by causing immunological imbalance, inflammatory storm, tissue damage with pulmonary impairment and potential dysfunction of multiple organs and disorders in the coagulation system. Even after the cure of COVID-19, in pregnant or postpartum women, add to the physiological changes characteristic of the period and may be exacerbated and/or responsible for a higher risk of complications or long-term gynecological or obstetric diseases.
\end{abstract}

\section{Keywords}

COVID-19, Maternal health, Health promotion

\section{Commentary}

SARS-CoV-2, responsible for the outbreak of severe acute respiratory syndrome corona virus 2 and the current pandemic, is one of seven species of coronavirus that infect humans and is among the three that are potentially fatal $[1,2]$. China's Wuhan province was considered the source of the outbreak and the World Health Organization declared a pandemic on January 30 , 2020 [3]. Until August 27, 2020, there were 24,021,218 cases of COVID-19 in the world and 821,462 deaths [3].

Since its discovery, symptoms have ranged from dry cough, fever, headache, asthenia, fatigue, diarrhea, emesis, respiratory distress and acute respiratory distress syndrome (ARDS) [4]. Its pathophysiology, although not fully understood, has been characterized by causing immunological imbalance, inflammatory storm, tissue damage with pulmonary impairment and potential dysfunction of multiple organs and disorders in the coagulation system $[5,6]$.

During pregnancy, when considering that there are physiological changes necessary to maintain the maternal-fetal interface and consequently to embryonic and fetal development, such as immunological, inflammatory and hypercoagubility changes [7], there may be greater susceptibility to infection or risk of exacerbation in the imbalances caused by the virus [8]. In the general population, including pregnant women, laboratory findings were: Elevation of inflammatory markers, such as interleukin (IL) -2, IL-6, IL-8, IL-10, tumor necrosis factor (TNF)- $\alpha, \mathrm{C}$-reactive protein (CRP) and ferritin, and markers of coagulation disorders, such as D-Dimer, platelets, fibrinogen and fibrin; in addition to changes in immunological markers, such as lymphocytes (TCD3 +, TCD4 +, TCD8 +, natural killer (NK) and regulatory $\mathrm{T}$ cells) and neutrophils, multiple organ dysfunction markers, such as creatinine, glutamic oxalacetic transaminase (TGO), glutamic transaminasepyruvic (TGP) and cardiac function enzymes $[9,10]$.

In pregnant women in the first trimester of pregnancy, due to the importance of immunotolerance for placentation, these changes may promote risk of

Citation: Silva JVF, Santos VE (2021) Imbalances Caused by SARS-CoV-2 during Pregnancy: Considerations for Long-Term Obstetric and Gynecological Care. Int J Womens Health Wellness 7:123. doi. org/10.23937/2474-1353/1510123

Accepted: June 28, 2021: Published: June 30, 2021

Copyright: (C) 2021 Silva JVF, et al. This is an open-access article distributed under the terms of the Creative Commons Attribution License, which permits unrestricted use, distribution, and reproduction in any medium, provided the original author and source are credited. 
disorders since placentation, with consequent damage to uteroplacental circulation and fetal development [11]. In those in the second or third trimester of pregnancy, on the other hand, there may be a greater risk of adverse events, such as those already identified in mothers infected with SARS-CoV-2: Prematurity, low birth weight, neonatal asphyxia, fetal death, neonatal death and newborn with a diagnosis of COVID-19 (even without knowledge about vertical transmission) [12].

In addition to obstetric complications and adverse neonatal outcomes in the active phase of infection, it is important to consider the importance of care and thorough continuity of follow-up after the diagnosis of cure due to the risk of long-term diseases, since, as in the lung, in heart and kidney, the transmembrane protein ACE2 (ACE homologue and part of the reninangiotensin system) and the cellular protease TMPRSS2 responsible for the entry of the virus into cells are also highly expressed in structures of the female reproductive system, such as ovaries, oocytes, uterus, placenta and placental villi [13].

In studies carried out with biopsies, for example, there is evidence of the severity and complexity of the damage caused to various organs by the infection, especially in patients with severe or severe cases. Regarding reproductive organ damage, there is still a lack of knowledge and data on biopsies have not been found, but in other organs the following damage has been reported: in the lungs, in addition to a higher concentration of ACE2, there was diffuse alveolar damage, microthrombi, pulmonary embolism and pulmonary hemorrhage; in the heart, there was acute myocardial infarction and myocardial hypertrophy; in the kidneys, there was acute tubular damage, hypertensive nephropathy and disseminated intravascular coagulation; in the liver, there was steatosis [14].

Some other studies corroborate these findings and emphasize endothelial dysfunction and the impact of coagulation imbalances, the immune system and the inflammatory response on organs affected and in the promotion of coagulation diseases, such as microthrombi and thromboembolias [6]. All these imbalances, even after the cure of COVID-19, in pregnant or postpartum women, add to the physiological changes characteristic of the period and may be exacerbated and/or responsible for a higher risk of complications or long-term gynecological or obstetric diseases.

Therefore, in addition to being important to mention that the severity of the disease and complications have varied according to the presence of risk factors, such as pre-existing comorbidities (hypertension, diabetes mellitus, obesity) [4], the scarcity of information about the disease, the lack of vaccine and medication with proven efficacy make it even more feared and impactful in the health. For those cured, during and after the pandemic, care must be maintained and public health services in each country must create public strategies and policies for investigating abnormalities and for early diagnosis and coping with possible long-term complications.

\section{Disclosures of Interest}

The authors report no disclosures.

\section{Funding}

This research did not receive any specific grant from funding agencies in the public, commercial, or not-forprofit sectors.

\section{Authors Contribution}

da Silva JVF and dos Santos Jr VE contributed equally in this manuscript: Manuscript draft, design, data interpretation, concept, text revision, and final approval.

\section{References}

1. Ludvigsson JF (2020) Systematic review of COVID-19 in children shows milder cases and a better prognosis than adults. Acta Paediatrica 109: 1088-1095.

2. Zhou P, Yang XL, Wang XG, Hu B, Zhang L, et al. (2020) A pneumonia outbreak associated with a new coronavirus of probable bat origin. Nature 579: 270-273.

3. World Health Organization (WHO) (2020) Coronavirus disease (COVID-19) outbreak situation.

4. Huang C, Wang Y, Li X, Ren L, Zhao J, et al. (2020) Clinical features of patients infected with 2019 novel coronavirus in Wuhan, China. Lancet 395: 497-506.

5. Lippi G, Plebani M (2020) Laboratory abnormalities in patients with COVID-2019 infection. Clinical chemistry and laboratory medicine 58: 1131-1134.

6. Connors JM, Levy JH (2020) COVID-19 and its implications for thrombosis and anticoagulation. Blood 135: 2033-2040.

7. Peixoto SM (2014) Manual de assistência pré-natal/Sérgio Peixoto. (2 ${ }^{\text {nd }}$ edn), Federação Brasileira das Associações de Ginecologia e Obstetrícia (FEBRASGO), São Paulo.

8. Zhao X, Jiang Y, Zhao Y, Xi H, Liu C, et al. (2020) Analysis of the susceptibility to COVID-19 in pregnancy and recommendations on potential drug screening. European journal of clinical microbiology \& infectious diseases 39 : 1209-1220.

9. Henry BM, de Oliveira M, Benoit S, Plebani M, Lippi G (2020) Hematologic, biochemical and immune biomarker abnormalities associated with severe illness and mortality in coronavirus disease 2019 (COVID-19): A metaanalysis. Clinical Chemistry and Laboratory Medicine 58: 1021-1028.

10. Qin C, Zhou L, Hu Z, Zhang S, Yang S, et al. (2020) Dysregulation of Immune Response in Patients With Coronavirus 2019 (COVID-19) in Wuhan, China. Clin Infect Dis 71: 762-768.

11. da Silva JVF, Silva KSC, dos Santos Junior VE (2020) SARS-CoV-2 in the first trimester of pregnancy: Potential interference in placentation. J Matern Fetal Neonatal Med 2020: 1 .

12. Yu N, Li W, Kang Q, Xiong Z, Wang S, et al. (2020) Clinical features and obstetric and neonatal outcomes of pregnant 
patients with COVID-19 in Wuhan, China: a retrospective, single-centre, descriptive study. Lancet Infect Dis 20: 559564.

13. Jing $Y$, Run-Qian L, Hao-Ran W, Hao-Ran C, Ya-Bin $\mathrm{L}$, et al. (2020) Potential influence of COVID-19/ACE2 on the female reproductive system. Molecular Human Reproduction 26: 367-373.
14. Menter T, Haslbauer JD, Nienhold R, Savic S, Hopfer H, et al. (2020) Postmortem examination of COVID-19 patients reveals diffuse alveolar damage with severe capillary congestion and variegated findings in lungs and other organs suggesting vascular dysfunction. Histopathology 77: 198-209. 